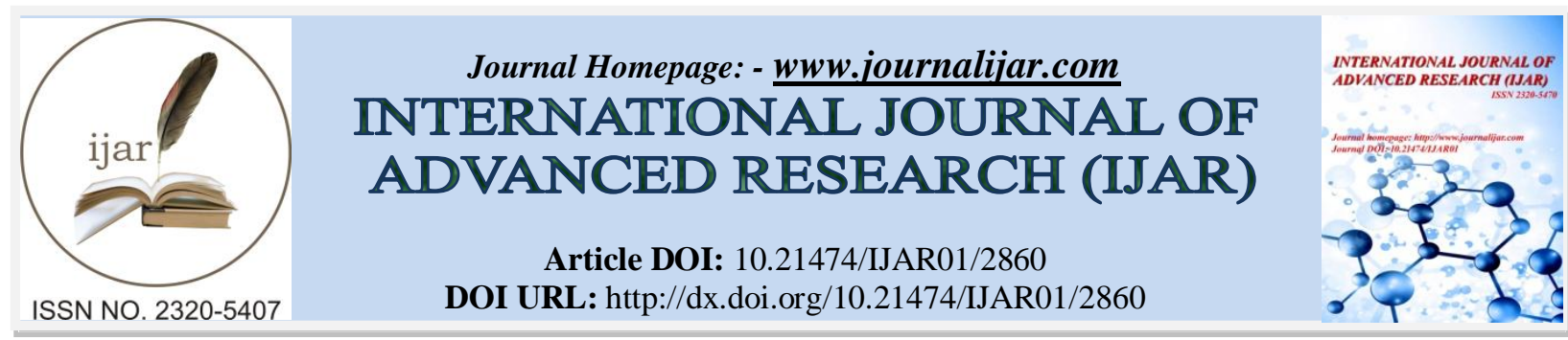

RESEARCH ARTICLE

\title{
EFFECT OF BACKGROUND PLASMA UPON PLASMA STRUCTURE FIRED FROM A PLASMA GUN
}

\author{
Subrata Samantaray ${ }^{1}$, Rita Paikaray ${ }^{2 *}$ And Joydeep Ghosh ${ }^{3}$. \\ 1. Department of Physics, Christ College, Cuttack, Orissa-753001, India. \\ 2. Department of Physics, Ravenshaw University, Cuttack, Orissa-753003, India. \\ 3. Institute for Plasma Research, Bhat, Gandhinagar, Gujarat-382428, India.
}

\section{Manuscript Info}

...........................

Manuscript History

Received: 21 November 2016

Final Accepted: 21 December 2016

Published: January 2017

Key words:-

Plasma gun, background plasma,

electron density, electron temperature

\section{Abstract}

Plasma gun is a very effective source to fire plasma structures and has a wide range of applications in optimization of plasma parameters of the plasma structure fired from plasma gun is an important field of research. The effect of background plasma upon plasma structure fired from a plasma gun is reported in this communication. It is observed that in the presence of background plasma both electron density and electron temperature of plasma structure is modified.

Copy Right, IJAR, 2016,. All rights reserved.

\section{Introduction:-}

Plasma guns have a wide range of applications in plasma physics and controlled fusion research. They provide high density plasmas for ion extraction [1]. They supply the target plasma in mirror experiments [2] and also help in the initiation of toroidal discharges [3]. They are widely used to accelerate pellets for fuelling fusion devices [4]. A variety of plasma guns have been developed and are in use since last half a century [5-14]. Optimization of plasma parameters in the structure fired from a plasma gun is an interesting field of research even today. Effect of another plasma source to fuel plasma structure fired from a plasma gun in worth discussing.

\section{Experimental:-}

The plasma gun used in this experiment consists of washer shaped electrodes which are made up of metal/alloys. Copper washer is used as anode and brass washer is used as cathode. In between the electrodes floating brass washers are stacked. The gas feed network injects desired gaseous substance into gun body to make it operational. Argon gas is used in this experiment. The gun is energized by a pulse forming network, which produces square wave pulse of $140 \mu \mathrm{s}$. The schematic diagram of plasma gun and allied circuit is shown in figure 1. An electromagnetic valve is used to inject gas into the gun from backside (cathode side). A low voltage capacitor bank was fired through a thyratron to generate a magnetic field in the vicinity of the mild steel piece and the resultant magnetization of the mild steel piece lifts the piston to allow the opening of the orifice and entry of the gas into the plasma gun. 


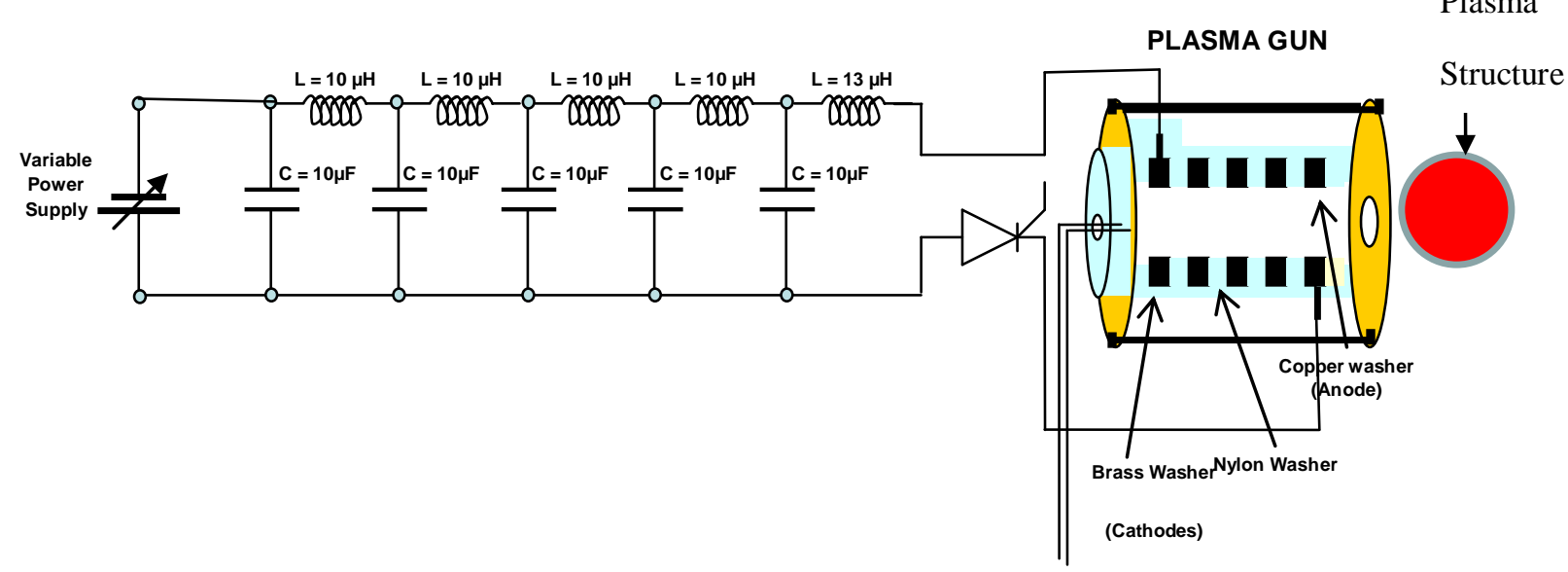

Figure 1:- Schematic diagram of plasma gun and allied circuit.

A background plasma set up is created [15] in the CPS device [16]. The effect of background plasma upon plasma parameters of the plasma structure fired from plasma gun is studied by means of different diagnostic tools. Langmuir probe is simple to fabricate, and is a very effective diagnostic tool to measure plasma parameters [17-18]. The biasing scheme of Langmuir probe is shown in figure 2. A piece of ceramic tube holds the tungsten probe/probes connected with copper wire/wires. Teflon pipe and tapes are used as insulation and holding material. These materials (tungsten, ceramic, teflon etc.) are able to withstand high temperature and are vacuum compatible. Ceramic is also resistant to sputtering and is an insulator.

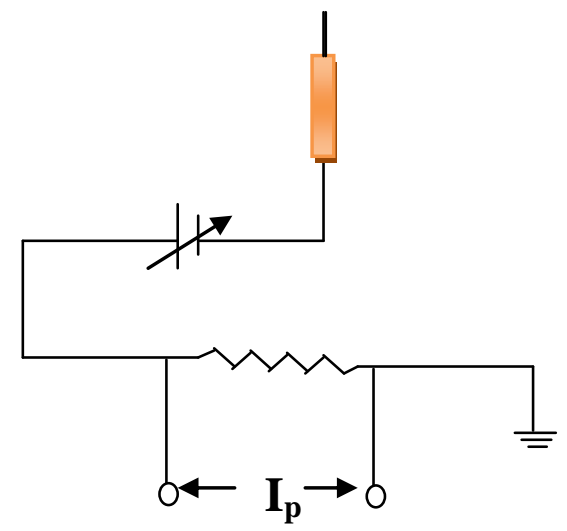

Figure 2:- Langmuir probe biasing scheme

\section{Results and Discussion:-}

Electron density of plasma is measured using Langmuir probe. If $I_{\text {sat }}$ is the electron current flowing through the circuit when probe is maintained at plasma potential and lower than floating potential then,

$\mathrm{I}=\mathrm{I}_{\mathrm{sat}} \exp (-\mathrm{eV} \mathrm{p} / \mathrm{kT})$

Where $\mathrm{T}, \mathrm{V}_{\mathrm{p}}, \mathrm{k}$ are the electron temperature, probe potential and Boltzmann Constant respectively.

$\mathrm{V}_{\mathrm{p}}=\mathrm{V}_{\mathrm{a}}-\mathrm{V}_{\mathrm{s}}$

$I_{\text {sat }}$ in terms of electron density is given by,

$I_{\text {sat }}=A_{p}$ e $n_{e} v=A_{p}$ e $n_{e}(k T / 2 m)^{1 / 2}$

Where $A_{p}, e, n_{e}, v$, and $m$ are the area of the probe, charge associated with an electron density, mean thermal velocity and mass of the electron respectively. Electron temperature is measured from the slope of $\mathrm{I} \sim \mathrm{V}$ curve.

The electron density is

$\mathrm{n}_{\mathrm{e}}=\left(\mathrm{I}_{\mathrm{sat}} / \mathrm{A}_{\mathrm{p}}\right)\left(2 \Pi \mathrm{m}_{\mathrm{e}} / \mathrm{e}^{3}\right)^{1 / 2}\left(\mathrm{e} / \mathrm{kT}_{\mathrm{e}}\right)^{1 / 2}$

Where, $A_{p}=\pi r^{2}+2 \pi r l=$ Area of the probe, $r$ and 1 are the radius and exposed length of the probe. 
The electron density of plasma fired from the plasma gun is found to be $9.7 \times 10^{16} \mathrm{~m}^{-3}$ at discharging potential 1.4 $\mathrm{kV}$ and ambient pressure $0.2 \mathrm{mb}$. The electron temperature is $\sim 1 \mathrm{eV}$. The probe is placed at $10 \mathrm{~cm}$ and $12.5 \mathrm{~cm}$ respectively from the plasma gun. When the background plasma system is turned on and plasma is fired from the gun across the background plasma, the peak electron density becomes $7.9 \times 10^{17} \mathrm{~m}^{-3}$ at a distance $10 \mathrm{~cm}$ from plasma gun, where the background plasma exists. The electron density of back ground plasma is $10^{13} \mathrm{~m}^{-3}$ for discharging potential $0.5 \mathrm{kV}$ [15]. The background plasma extends from $8 \mathrm{~cm}$ from plasma gun to $12 \mathrm{~cm}$, as the parallel plate used in back ground plasma is around $4 \mathrm{~cm}$ wide. On the other hand at a distance $12.5 \mathrm{~cm}$ from plasma gun where the periphery of background plasma region exists, the electron density of plasma is found to be $1.9 \mathrm{X}$ $10^{17} \mathrm{~m}^{-3}$. The electron density profiles of plasma in the absence and presence of background plasma is shown in figures 4 and 5 respectively.

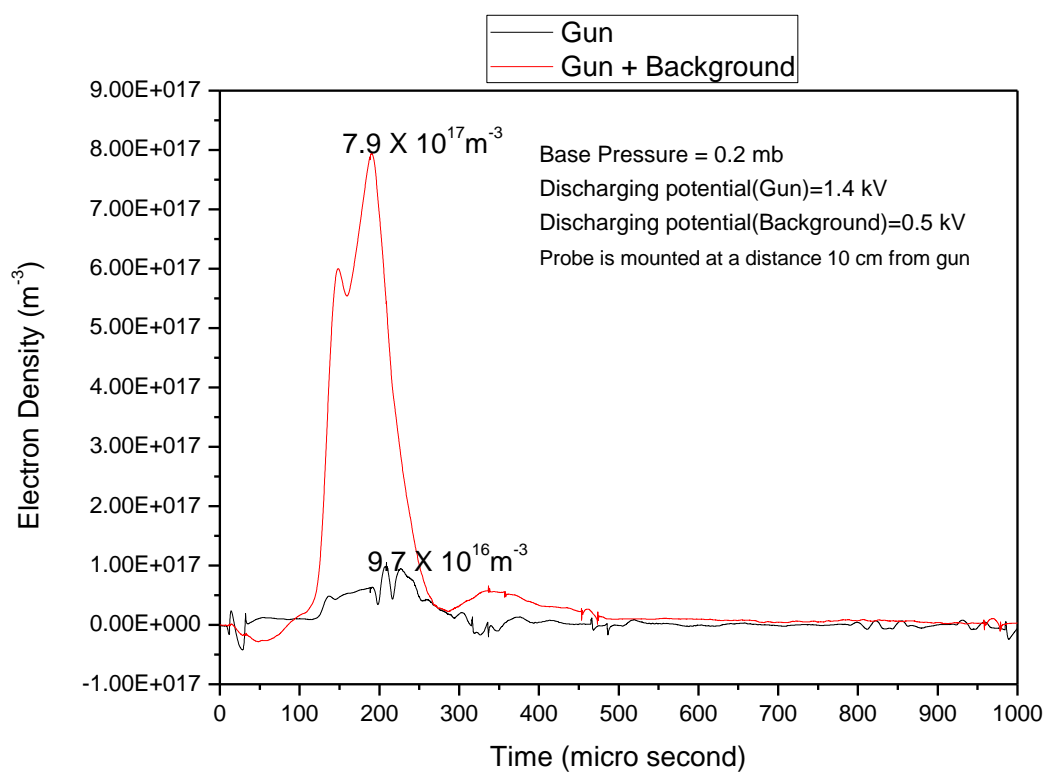

Figure 3:- Electron density profile of argon plasma at a distance $10 \mathrm{~cm}$ from plasma gun

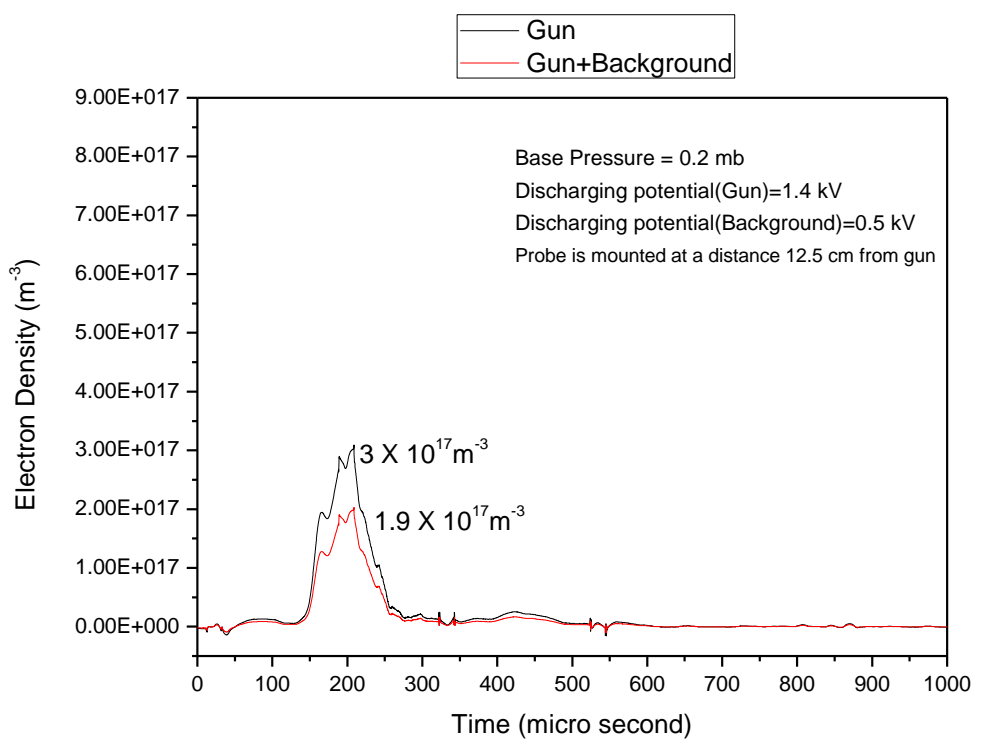

Figure 4:- Electron density profile of argon plasma at a distance $12.5 \mathrm{~cm}$ from plasma gun 
Image of plasma structure gives a lot of information [19]. The image of background plasma is shown in figure 5 and the image of plasma fired from plasma gun in the presence of background plasma is shown in figure 6. The plasma structure inside background plasma region becomes more intense, which is evident from the images. The density of plasma structure increases, being fueled by background plasma, ten times as shown in figure 3. So, external plasma near gun mouth will enhance the plasma density and this will be very helpful for the experimenters using plasma guns in fusion devices. Parallel plate type as well as filament plasma can be used as external plasma source for a plasma gun, for its optimization.

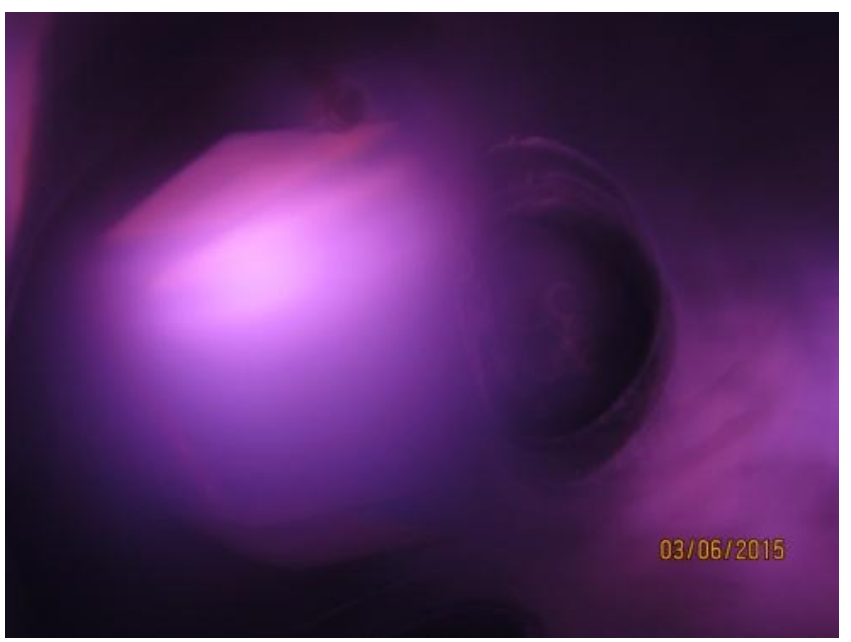

Figure 5:- Image of background plasma

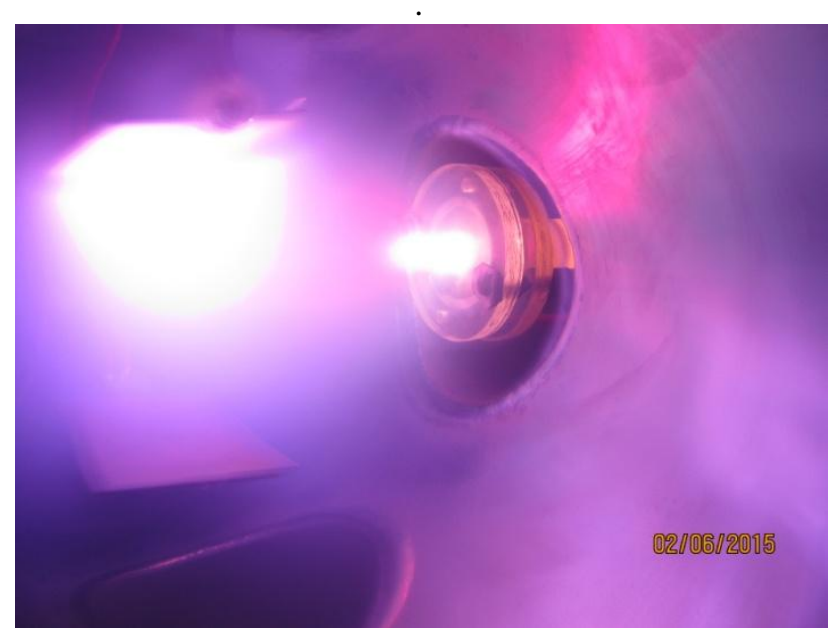

Figure 6:- Image of plasma from plasma gun in the presence of background plasma.

\section{Conclusion:-}

Background plasma enhances plasma density of the structure fired from plasma gun. The electron density of plasma structure increases ten times, when fueled by background plasma of density thousand times less than that of plasma produced from plasma gun. The electron temperature is modified in the presence of back ground plasma. External plasma source will enhances the parameters of the plasma structure from plasma gun for fusion devices.

\section{Acknowledgement:-}

The work is funded by BRNS-PFRC, Govt of India under National Fusion Program 


\section{References:-}

1. M. Dembinski, P. K. John and A. G. Ponomarenko Appl. Phys. Lett. 34, 553 (1979).

2. F. H. Coensgen et al. Phys. Rev. Lett. 37,143 (1976).

3. R. Prater, R. Lattaye, S. Wong, S. Ejima, C. Moeller and P. Peterson EPRI Report ER-215 (1976).

4. T. H. Buller, R. J. Turnbull and K. Kim, Appl. Phys. Lett. 34, 7268 (1979).

5. M. Alidieres, R. Aymar, Ph. Jourdan, F. Koechlin and A. Samain, Phys. Fluids Vol. 6, 407 (1963).

6. J. F. Steinhaus, N. L. Oleson and W. L. Barr, Phys Fluids 8,1720 (1965).

7. H. Himura, Y. Saito, A. Sanpei, S. Masamune, N. Takeuchi and T. Shiono, Rev. Sci. Instrum. 77, 073506 (2006).

8. A. V. Voronin and K. G. Hellblom, Plasma Phys. and Controlled Fusion vol. 41, 293 (1999).

9. P. F. Little and B. E. Avis, J. Nucl. Energy, Part C, Plasma Phys 8,11 (1966).

10. Dah. Yu Cheng, Nucl. Fusion vol. 10, 305 (1970) .

11. T. Asai, H. Itagaki, H. Numasawa, Y. Terashima, Y. Hirano and A. Hirose, Rev. Sci. Instrum. 81, 10E119: 1 (2010).

12. A. BenAmar Baranga, A. Fisher and D. Tzach, Rev. Sci. Instrum. 56, 1472 (1985).

13. K. K. Jain, P. I. John, A. M. Punithavelu and P. P. Rao, J. Phys. E: Sci. Instrum. 13, 928 (1980).

14. J. E. Osher, Rev. Sci. Instrum. 53, 1685 (1982).

15. S. Samantaray, R. Paikaray, G. Sahoo, P. Das and J. Ghosh, Res. J. Phys. Sciences, 3 (6), 10, (2015).

16. G. Sahoo et al., Applied Mechanics and materials, 278-280, 90 (2013)

17. F. F. Chen, "Electrostatic Probes in Plasma Diagnostic Techniques" ed R H . Huddlestone and S. L. Leonard (Academic Press), (1965).

18. I. H. Huchinson, "Principle of Plasma Diagnostics", Cambridge University Press, (1987).

19. G. Sahoo, R. Paikaray and S. Samantaray, International Journal of Advanced Research, 2(11), 438 (2014) 